\title{
Feed Hungry, Feel Happy
}

Yadnesh Chaudhari*, Niraj Rawat, Tejas Nikhar, Prof. Saumya Salian

Department of Computer Engineering, Datta Meghe College of Engineering Airoli, Navi Mumbai, Maharashtra, India

\section{ABSTRACT}

Article Info

Volume 7, Issue 3

Page Number: 358-363

Publication Issue :

May-June-2021

\section{Article History}

Accepted : 20 May 2021

Published : 29 May 2021
The sharp increase within the quantity of wastage in terms of food makes the requirement for charity in terms of donation. within the current situation food is being wasted daily on an outsized basis in numerous restaurants, weddings, social functions, faculty canteens and plenty of different social events. individuals give food manually by visiting every organization range of times so as to cut back the issues of food wastage whereas their area unit websites that have taken efforts to assist individuals give food. The planned system presents, a replacement internet-based application that gives a platform for donating leftover food to all or any poverty-stricken people/organizations. The system is shown to be an efficient suggests that of donating things to organizations, etc. over the web. It shows the potential for avoiding the wastage of food. It provides data regarding the motivation to return up with such associate application, thereby describing existing donation system and the way the merchandise works for betterment of the society. this technique can produce a standard collaboration portal for hotels/restaurants and charities, charity will directly contact edifices who have food remaining and report generation which can show what quantity food is given by that restaurant and providing reward points for them .In this system Food Donor, Food receiver, Third party merchandiser, admin and premium user area unit the most modules wherever Food Donor may be any organization, institute or faculty who desires to give food and build a replacement food donation request and Food receiver may be any charity firm seeking for food. a replacement food donation request are going to be created on the portal and once the request is accepted, a notification is distributed.

Keywords : Food Donation, Charity, Social Work

\section{INTRODUCTION}

In extremely inhabited countries like India, food wastage could be a troubling issue. The streets, garbage bins and landfills have ample proof to prove it. Marriages, canteens, restaurants, social and family get-togethers and functions expel out most food.
Food wastage isn't solely a sign of hunger or pollution, however conjointly of the many economic issues. The high commonplace of living has resulted within the wastage of food, clothes, etc. thanks to fast changes in habits and way rather than wasting this stuff we will place them in use by donating them to varied organizations like orphanages, adulthood homes, etc.

Copyright: @ the author(s), publisher and licensee Technoscience Academy. This is an open-access article distributed under the terms of the Creative Commons Attribution Non-Commercial License, which permits unrestricted non-commercial use, 
the merchandise could be a internet application that aims to determine a link between restaurants and also the charity homes/needy households to alter excess food donation.

Food donation portal is internet-based application that has a platform for donating leftover food to all or any destitute people/organizations. The portal is shown to be a good suggests that of donating food to organizations, etc. over the net. In extremely inhabited countries like India, food wastage could be a massive issue. the rubbish bins, streets and landfills have ample proof to prove it. Canteens, marriages, restaurants, social and family get-togethers and functions expel out most food. Food wastage isn't solely a sign of pollution or hunger, however conjointly of the many economic issues. The high commonplace of living has resulted within the wastage of food. thanks to fast changes in habits and way rather than wasting food, the system will place them in use by donating them to varied organizations like adulthood homes, orphanages, etc. the merchandise is associate internet-based web site application that essentially aims at charity through donations.

Many individuals, institutes want to present things to necessitous organizations. Also, several organizations want to kindle varied things needed by them like garments, food grains, utensils, etc. however there's no supply obtainable through that they'll satisfy their needs. Thereby, associate internet primarily based application has been developed through which individuals will present food things as per their capability application also permits organizations to place up their requests, that's things needed by them, if any.

\section{LITERATURE REVIEW}

\section{A. Leloca Application}

LELOCA is associate degree application to scale back the quantity of food waste in restaurants. Leloca provides a geo-localized eating coupons by tagging them on the map. during this method, restaurants decrease their surplus waste. In this application the food is rather needed to be purchased then giving it free.

\section{B. Ratatouille}

RATATOUILLE was developed to figure at personal consumption level and permit folks to give food from their refrigerator. The application uses geolocation to show nearest refrigerator associated offers an termination date for every food donation. In addition, Ratatouille is employed by hostels and students World Health Organization area unit conversant in share leftovers.

\section{Share The Meal}

ShareTheMeal is Associate in Nursing initiative of the international organization World Food Program (WFP) - the world's largest humanitarian agency fighting hunger. Each year, WFP reaches over eighty-six million folks with food help in around eighty-three countries. WFP is 100 percent voluntarily funded, therefore each donation counts. Donations from the ShareTheMeal app support numerous WFP operations starting from resilience building and faculty feeding programmes to providing food help in emergencies. Since launching the app in 2015, they need helped give aid to a number of the most important food crises within the world as well as Yemen, Asian nation and Federal Republic of Nigeria.

\section{Breading}

In a completely different study BREADING was developed to minimize bread leftovers at bakeries. 
the appliance permits bakers to gift their leftover bread and manage its assortment method. The donation area unit geo-localized for close collectors to urge noticed.

\section{Technology Description}

\section{A. React}

React (also referred to as React.js or ReactJS) is associate degree ASCII text file, front end, JavaScript library for building user interfaces or UI elements. React is merely involved with state management and rendering that state to the DOM, therefore making React applications typically needs the utilization of further libraries for routing, further as bound clientside practicality the libraries utilized in react includes "ant design, react-router-dom, redux, redux-saga".

\section{B. React Native}

The operating principles of React Native area unit nearly a twin of React except that React Native does not manipulate the DOM via the Virtual DOM. It runs during a background method (which interprets the JavaScript written by the developers) directly on the end-device and communicates with the native platform via serialized information over an asynchronous and batched bridge. React parts wrap existing native code and move with native Api's via React's declarative UI paradigm and JavaScript. It Includes libraries "react-navigation, redux, reduxsaga".

\section{Node.js Server}

Node.js is AN ASCII text file, cross-platform, backend JavaScript runtime atmosphere that runs on the V8 engine and executes JavaScript code outside an internet browser.

Express, could be a back-end internet application framework for Node.js, discharged as free and ASCII text file computer code underneath the MIT License. it's designed for building internet applications and Api's.

\section{MongoDB}

MongoDB could be a source-available cross-platform document-oriented database program. Classified as a NoSQL database program, MongoDB uses JSON-like documents with nonmandatory schemas. MongoDB atlas is a cloud database storage provided by the MongoDB Community.

\section{E. Firebase}

Firebase is a platform developed by Google for making mobile and internet applications. In our application we've used it to inform the users.

\section{Food Fully (Proposed System)}

The planned application Food donation portal is internet-based application that has a platform for donating leftover food to any or all poor people/organizations, the merchandise is shown to be a good suggests that of donating things to organizations, etc. over the net. In extremely inhabited countries like India, food wastage could be a heavy issue. Marriages, canteens, restaurants, social and family get-togethers and functions expel out most food, rather than wasting this stuff the system will place them in use by donating them to varied organizations like orphanages, adulthood homes, etc. the merchandise is associate degree internet-based web site application that primarily aims at charity through donations many folks, institutes want to gift things to poor organizations. Also, several organizations want to enkindle varied things needed by them like garments, food grains, books, utensils, etc., however there's no supply accessible through that they will satisfy their needs. 


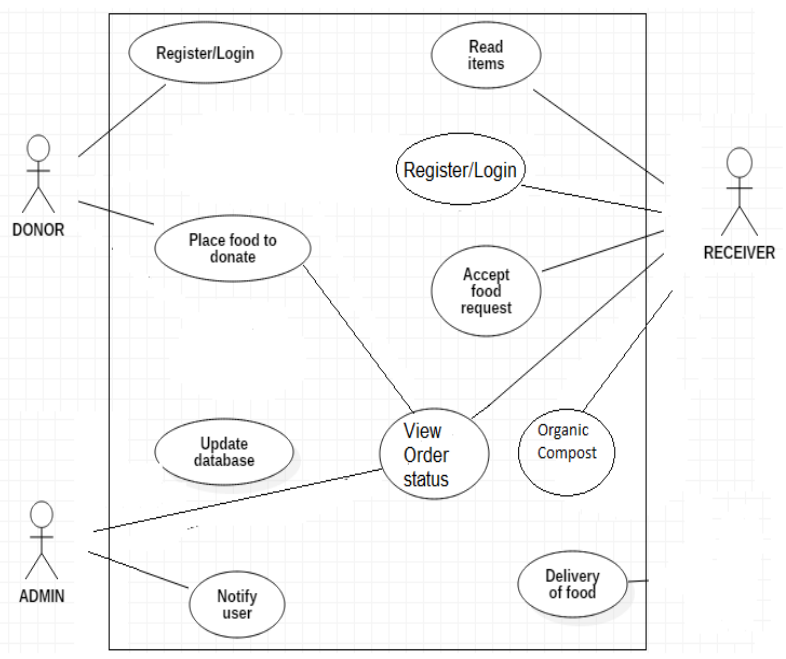

Figure 1 : Use case Diagram

Thereby, associate degree internet primarily based application has been developed through which individuals will gift food things as per their capability. This product additionally helps in making organic compost of the left-over spoiled food which may be used for tree plantation. Food wastage reduction through donation" product is developed as an honest implies that of donating things to organizations (Charities), etc. over the online. It shows the potential for avoiding the wastage of food. This application is internet primarily based, developed using React framework and needs web affiliation and can give a platform for donors and seekers when they with success register into the system. each donor and seekers need to be registered and attested before they will continue exploitation the system for donation purpose.

\section{Working Of Application}

This application primarily consists of three actors Donor, Receiver and Admin. In Fig1., the Donor performs operations like Registration and Login into the System. The Donor may be any institute who needs to give food and can place up their request to the portal. This message is shown as notification within the portal to alternative users (NGOs). This message is hold on in backend within the database (MongoDB). Food Receiver may be any NGOs/Charity firm who wants food can check for any food donation request on the portal and may settle for that request if required. The admin also can monitor and update the information. The Admin and Receiver each will read the Donor's Order. The remaining left over spoiled food are going to be pay to organic compost producer to form organic compost which might be used for trees.

This way project can fill the gap between the food and save food. The projected application shall scale back food wastage and conjointly fulfill alternative necessities like food things of necessitous organizations. At present, the projected system is attending to avoid the key wastage that sometimes happens in India which is foodstuffs. The system is anticipated to update and refine constant which can facilitate to feature up potency and utility of the applying.

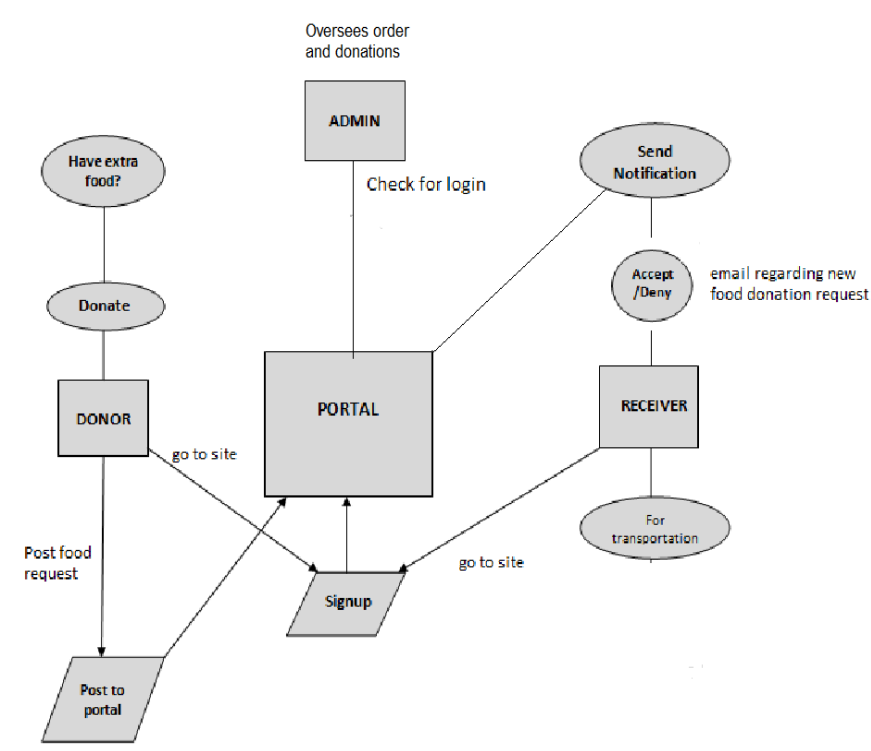

Figure 2 : Project Workflow 
Web Design Figures

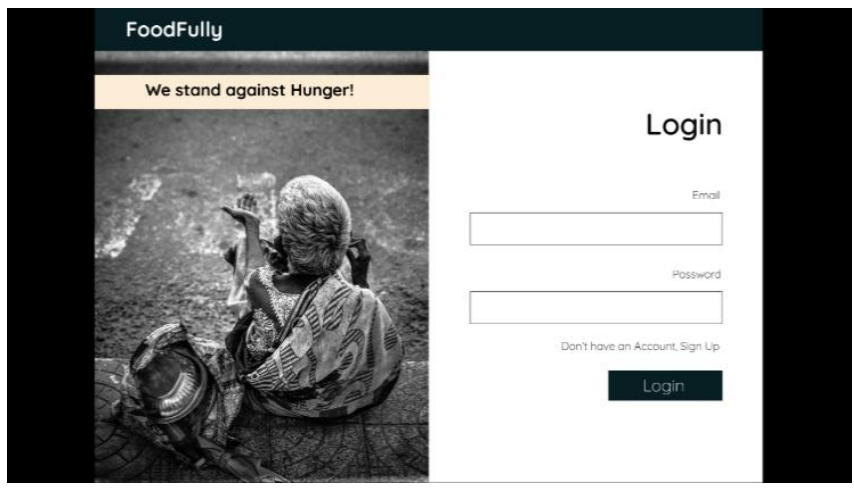

Login Page

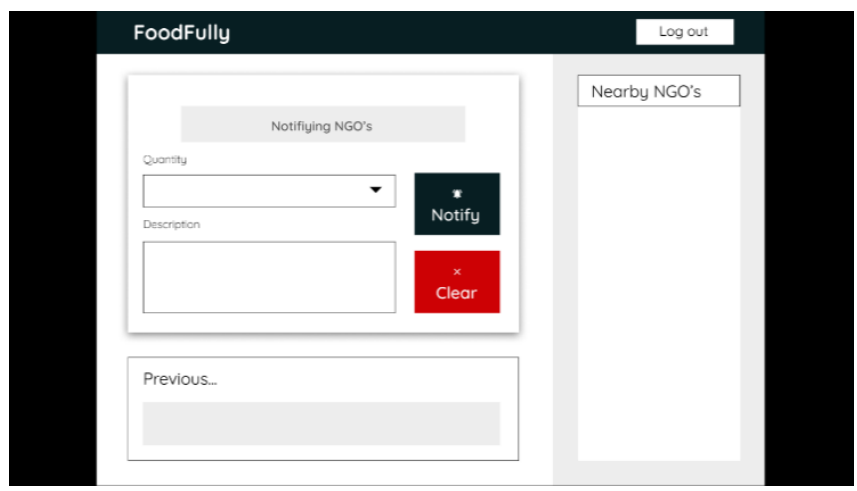

Hotel page

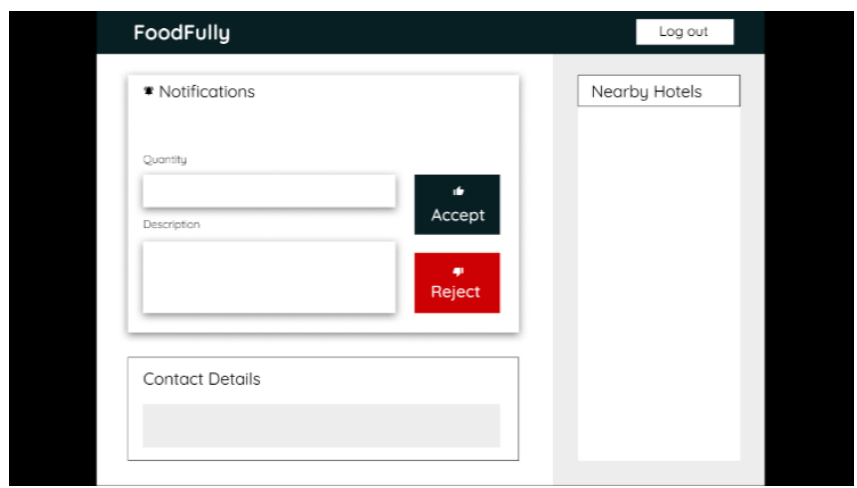

NGO Page

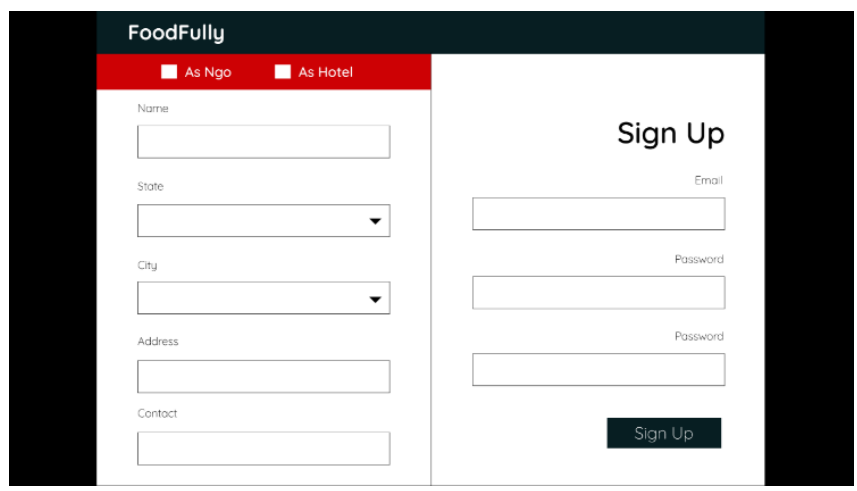

Signup Page

Application Pages

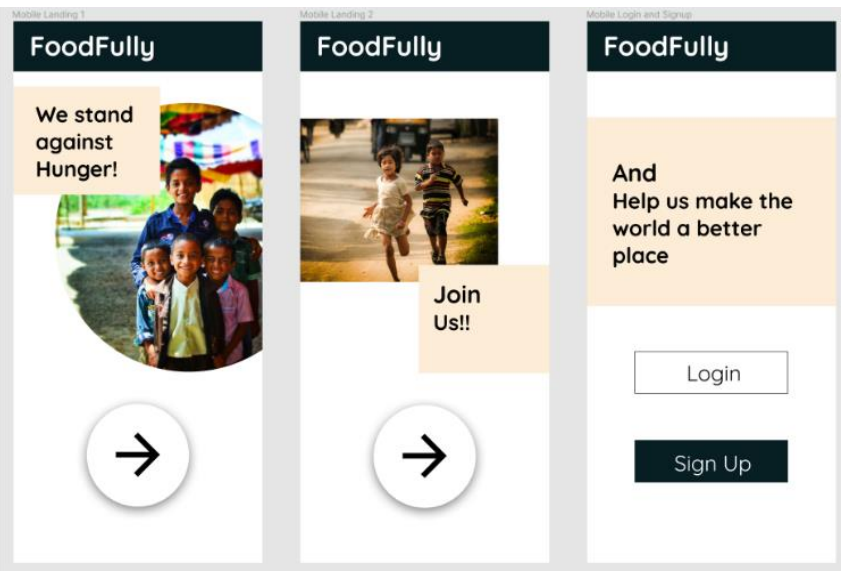

Mobile Landing Page

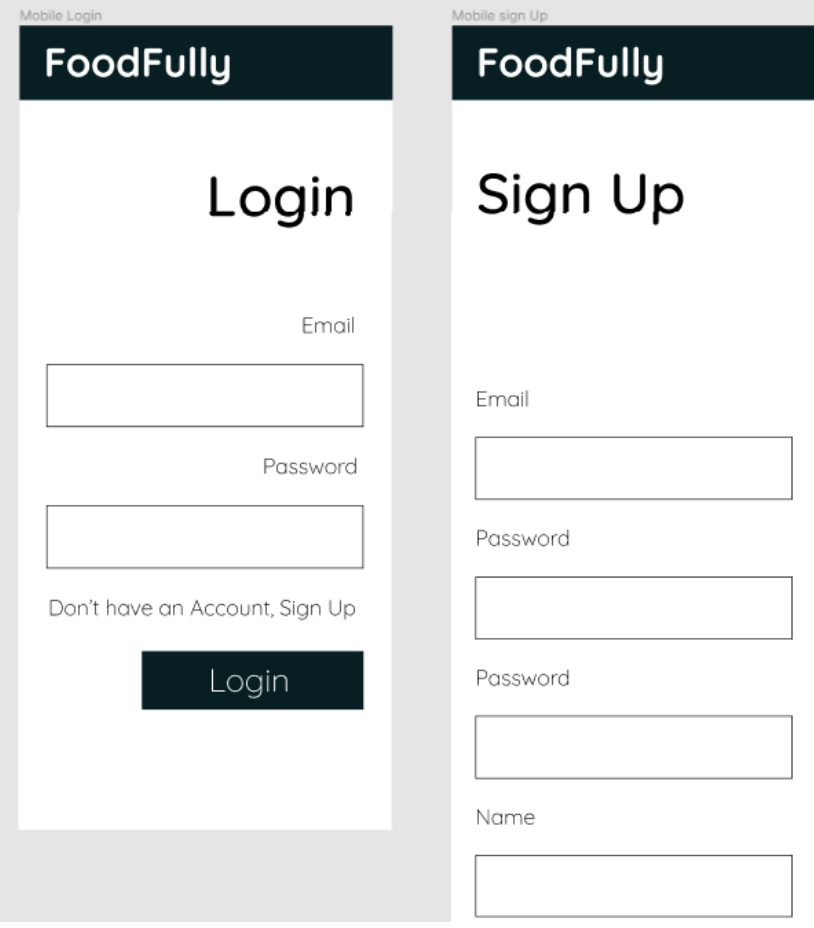

Mobile Login/Signup Page 


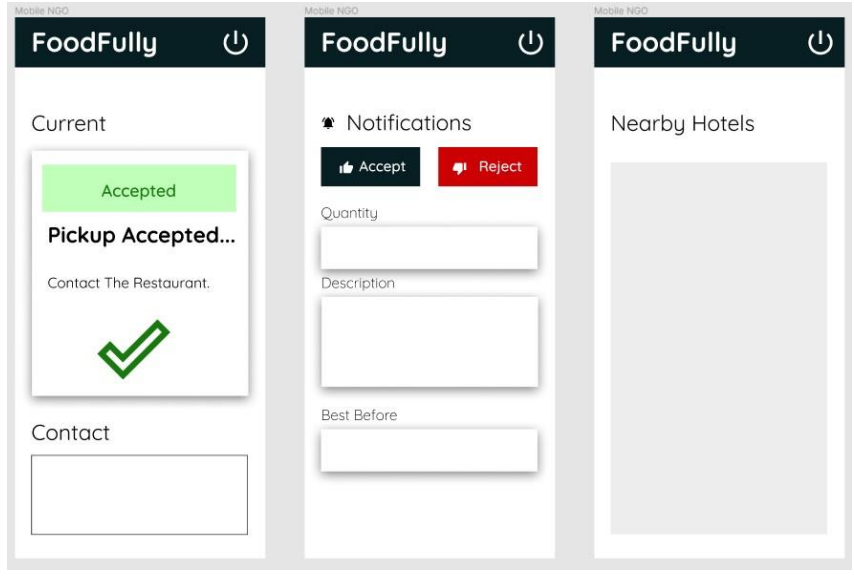

NGO Page

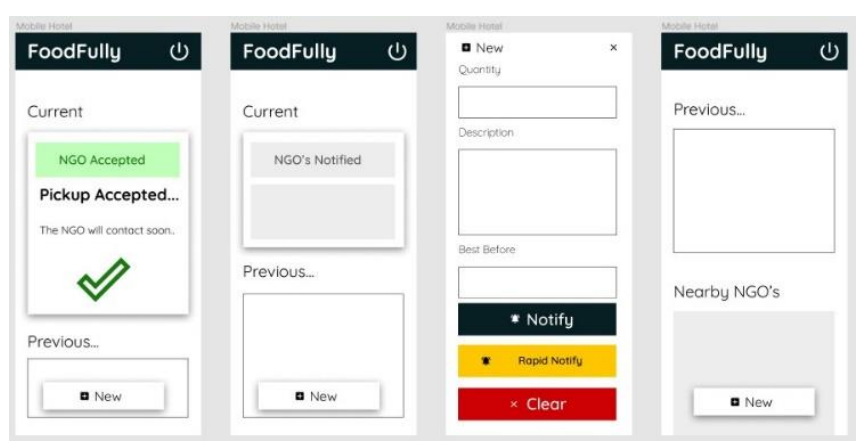

Hotel Page

\section{Conclusion and Future Scope}

The development of this product sure prompts several new areas of investigation. This product has wide scope of implementation by creating it live. Furthermore, this product creates several edges for the business and also the community. By taking it online it'll facilitate many folks throughout town by donating food daily.

Hundreds of thousands of plenty of food area unit either lost or wasted whereas a lot of individuals suffer from deficiency disease. A plausible initiative is that the food donation portal within which giant retail chains and probably different organizations will give food. This food is collected and delivered to nongovernmental organization in would like. Food donation portal can facilitate thousands of individuals that suffer from starvation and additionally consume food that area unit wasted with no reason. As consequence, analysis and actions area unit required to boost the potency of food donation portal.

\section{REFERENCES}

[1]. Rucha Jadhav, Priyal Kulkarni, Komal Pagere's "System to Reduce and Manage Food Waste. https://www.irjet.net/archives/V6/i12/IRJETV6I1296.pdf

[2]. J Manikandan and Mr. N Kumar's "Food Wastage Reduction Through Donation". https://www.irjet.net/archives/V7/i3/IRJETV7I378.pdf

[3]. UNICEF's "Share the Meal" https://sharethemeal.org/en/values.html

\section{Cite this article as :}

Yadnesh Chaudhari, Niraj Rawat, Tejas Nikhar, Prof. Saumya Salian, "Feed Hungry, Feel Happy", International Journal of Scientific Research in Computer Science, Engineering and Information Technology (IJSRCSEIT), ISSN : 2456-3307, Volume 7 Issue 3, pp. 358-363, May-June 2021. Available at doi : https://doi.org/10.32628/CSEIT217388 Journal URL : https://jisrcseit.com/CSEIT217388 